\title{
Management of malignant pleural mesothelioma: a French multicenter retrospective study (GFPC 0802 study)
}

C. Raynaud ', L. Greillier ${ }^{2}$, J. Mazieres ${ }^{3}$, I. Monnet ${ }^{4}$, B. Mastroianni ${ }^{5}$, G. Robinet ${ }^{6}$, G. Fraboulet ${ }^{7}$, A. Dixmier ${ }^{8}$, H. Berard ${ }^{9}$, R. Lamy ${ }^{10}$, J. Letreut ${ }^{11}$, H. Lena ${ }^{12}$, G. Oliviero ${ }^{13}$, S. Botta ${ }^{14}$, A. Vergnenegre ${ }^{15}$, I. Borget ${ }^{16}$ and C. Chouaid ${ }^{4 *}$

\begin{abstract}
Background: Malignant pleural mesothelioma (MPM) is a rare disease with poor prognosis in spite of significant improvement in survival, due to new chemotherapy regimens. We describe here patients' profiles and management in daily practice in France.

Methods: Observational retrospective study. Data were collected from medical files. All patients with histologically proven MPM diagnosed from January 2005 to December 2008 were included in the participating sites.

Results: Four hundred and six patients were included in 37 sites: mean age $68.9 \pm 9.8$ years, male predominance (sex ratio 3.27), latency of the disease 45.7 years, epithelioïd type $83 \%$. Diagnosis was made using thoracoscopy in $80.8 \%$ of patients. Radical surgery was performed in $6.2 \%$ of cases. Chemotherapy was administered to $74.6 \%$ of patients. First line regimens consisted mainly of platinum + pemetrexed (91\%) or pemetrexed alone (7\%). Objective response rate was $17.2 \%$ and another $41.6 \%$ of patients experienced disease stabilization. Half of these patients underwent second line chemotherapy (platinium + pemetrexed $31.6 \%$, pemetrexed alone $24.6 \%$ ), resulting in a $6 \%$ response rate. Third-line chemotherapy (56 patients) yielded disease control in $5.4 \%$ of cases.
\end{abstract}

Conclusions: The management of MPM in France is usually in accordance with guidelines. Response rates are somewhat lower than those described in clinical trials.

Keywords: Malignant pleural mesothelioma, Treatment, Chemotherapy

\section{Background}

Malignant pleural mesothelioma (MPM) is a rare aggressive tumor. Since it is mainly associated with asbestos exposure, its incidence varies among countries and population subgroups, depending on the degree of exposure.

The time between exposure and diagnosis of MPM often exceeds several decades. It has been shown recently that the risk continues to rise until 45 years following exposure [1]. The incidence of MPM is continuously increasing in some contries as Australia and United Kingdom [2-4] but remains very stable for over 5 years in U.S. and Japan. In France, the epidemiological pattern is different since asbestos use has been strictly

\footnotetext{
* Correspondence: christos.chouaid@chicreteil.fr

${ }^{4}$ Service de pneumologie, CHI Créteil, 40 avenue de verdun, 94010 Créteil, France

Full list of author information is available at the end of the article
}

controlled as early as 1978 and definitely forbidden in 1997. New cases are still diagnosed due to the long latency of the disease, but apparently, the incidence peak has been reached in 2000-2005 for men [5]. However, in the meantime, the incidence is still increasing in women, in whom professional exposure is often missing. The number of MPM-related deaths is approximately 1100/ year in men and 300/year in women in France [5] while the incidence ranges from less than $1 /$ million for the general population to $50-100 /$ million for at-risk subgroups [5]. A national network has been created in 1998 (PNSM: Programme National de Surveillance des Mésothéliomes) for epidemiological observation, clinical research and organization of healthcare supply [6]. Apart from the well-known occupational exposure, environmental exposure to asbestos or other carcinogenic compounds remains to be explained while they seem to 
account for more and more cases [4]. No oncogenic driver has been identified and molecular pathways leading to MPM are also unclear, so that up to now, there is no evidence for using specific targeted therapies in the treatment of these tumors and most clinical trials yielded negative outcomes [7]. Extrapleural pneumonectomy preceded by neoadjuvant chemotherapy and followed by hemithorax irradiation has been almost abandoned in routine practice, since several clinical trials have demonstrated low feasibility, absence of survival benefits and unacceptable postoperative morbimortality $[8,9]$. Treatment of advanced diseases relies primarily on chemotherapy with a combination of platinum and pemetrexed until the results of ongoing clinical trials provide information that may change our practice (association with bevacizumab,new targeted therapies or immunotherapy).

The objective of our study was to describe the patients' profiles and the management of MPM in France, as regards diagnosis and treatment.

\section{Methods}

In this observational national multicenter study, we retrospectively reviewed the medical files of patients diagnosed and treated in France. All the sites belonging to the GFPC (French Group of Onco-Pneumology) were invited to participate. Patients were included if they had a histologically proven MPM diagnosed between January 2005 and December 2008, and if they had been managed in the participating site. Patients who were treated for recurrent mesothelioma during this period were excluded if the diagnosis had been made before January 2005. The following information was recorded: patients' demographics, smoking status and medical history, exposure to asbestos (assess by a specific questionnaire), symptoms, diagnostic procedures, type of treatment (surgery, radiation therapy and chemotherapy) and response to treatment, as evaluated by local investigators.

Descriptive statistics were used, namely means, standard deviations, medians and ranges for quantitative variables, counts and percentages for categorical variables. No statistic tests were performed. The date of last observation was December 31, 2008. The protocol was approved by the CHU Limoges ethics committee, on behalf of all participating centers, and the study complied with good clinical practice and the Helsinki Declaration. All participants signed informed consent.

\section{Results}

We included 406 patients diagnosed and managed at 37 sites (203 cases in 16 teaching hospitals, 183 in 18 general hospitals, 14 in 2 cancer research centers and 6 in one military hospital). Their main characteristics are summarized in Table 1 . Men accounted for $77 \%$ of the
Table 1 Main characteristics of patients $(n=406)$

\begin{tabular}{ll}
\hline Age at diagnosis, years (mean + SD) & $68.9 \pm 9.8$ \\
Gender, male & $76.6 \%$ \\
Smoking status $(n=367)$ & \\
$\quad$ Never smoker, $n(\%)$ & $152(42.4 \%)$ \\
$\quad$ Current smoker, $\mathrm{n}(\%)$ & $36(9.8 \%)$ \\
Past smoker, $\mathrm{n}(\%)$ & $179(48.8 \%)$ \\
Pack-years, mean \pm SD & $28 \pm 17.1$ \\
Medical history, $\mathrm{n}(\%)$ & \\
$\quad$ Cancer & $40(9.8 \%)$ \\
Chronic obstructive pulmonary disease & $17(4.2 \%)$ \\
Cardiovascular disorders & $69(17.0 \%)$ \\
High blood pressure & $153(37.7 \%)$ \\
Neurovascular disorders & $15(3.7 \%)$ \\
$\quad$ Asbestosis & $7(1.1 \%)$ \\
Diabetes mellitus & $54(13.0 \%)$ \\
Symptomatic at diagnosis $(n=373), \mathrm{n}(\%)$ & \\
Yes & $347(93.0 \%)$ \\
Dyspnea & $248(71.5 \%)$ \\
Thoracic pain & $154(44.4 \%)$ \\
Other & $158(45.5 \%)$ \\
Exposure to asbestos $(n=406), \mathrm{n}(\%)$ & $259(63.8 \%)$ \\
Type of exposure $(n=259)$ & \\
Professional & $251(96.9 \%)$ \\
Environmental & \\
\hline
\end{tabular}

cohort; most frequent comorbidities were high blood pressure (37.7 \%) and cardiovascular diseases (17\%). A majority of patients had respiratory symptoms at diagnosis (93\%), mainly dyspnea and thoracic pain. A previous exposure to asbestos was identified in $64 \%$ of cases and the mean time from exposure to diagnosis was 45.7 years.

Examinations performed for disease staging included thoracic CT scan (98\%), abdomino-pelvic CT scan (65\%), echocardiography (22\%), PET-scan (24\%) and magnetic resonance imaging (10\%). Diagnosis was based on surgical thoracoscopic/pleuroscopic biopsy in most cases (Table 2). The epithelioïd type was the most frequent $(82.9 \%)$ followed by sarcomatoid $(10 \%)$ and mixed or biphasic (7.1\%) types.

Only 30 patients underwent curative surgery, namely extra-pleural pneumonectomy and pleurectomy in 25 and 5 cases respectively. In addition, pleurodesis was performed in 191 patients. Two hundred and sixty-eight patients had prophylactic drain site radiation therapy with a mean number of $5.2 \pm 6.2$ sessions and a mean number of $6 \pm 2.2$ Gy per session.

First-line chemotherapy was administered to 303 (74.6\%) patients, among whom $162(53.5 \%)$ and 56 $(18.5 \%)$ had second- and third-line chemotherapy 
Table 2 Diagnostic procedures $(n=406)$

\begin{tabular}{ll}
\hline Blind closed pleural needle biopsy with local anesthesia & $16(3.9 \%)$ \\
Medical thoracoscopic biopsy & $11(2.7 \%)$ \\
Surgical thoracoscopic biopsy & $317(78.1 \%)$ \\
Biopsy by thoracotomy & $45(11.1 \%)$ \\
CT-scan guided blind closed pleural needle biopsy & $16(4 \%)$ \\
Unknown & $1(0.2 \%)$ \\
\hline
\end{tabular}

respectively (Fig. 1). Most frequently used chemotherapy regimens were cisplatin - pemetrexed in first line, and gemcitabine as single agent in $2^{\text {nd }}$ and $3^{\text {rd }}$ line (Fig. 2).

The mean (median) numbers of cycles were $4.7 \pm 1.7$ [6], $3.5 \pm 1.9$ [3] and $3.1 \pm 2$ [3] in first, second and third lines respectively. The percentage of patients who responded to or were stabilized by treatment decreased over line, from $60.1 \%$ in first line to $5.3 \%$ in third line chemotherapy (Table 3).

\section{Discussion}

We described here patients' characteristics and management of MPM in France. This patient cohort represent only $10 \%$ of all patients diagnosed and treated in France; but it should be highlighted that all high volume centers participated and the remaining patients are treated individually throughout the country in centers with very low volumes. Since MPM is a rare disease, there are few such reports in the literature. A Turkish series of 228 patients diagnosed and followed from 1993 to 2010 was published in 2012 [10]. Age at diagnosis was 10 years younger in the Turkish cohort (59 years) and sex ratio was only 1.4 in favor of men. The type of exposure was probably different since most patients were farmers and housewives, and lived in rural areas. Diagnostic procedures were also different since blind closed pleural needle biopsy was performed in more than one half of patients and thoracoscopy in only $3 \%$. In another Turkish cohort of 54 patients from a single

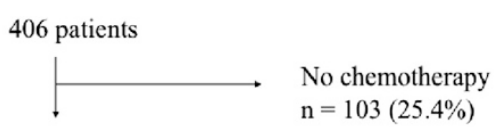

$1^{\text {st }}$ line chemotherapy, $\mathrm{n}=303(74.6 \%)$

Number of cycles: $4.7 \pm 1.7$

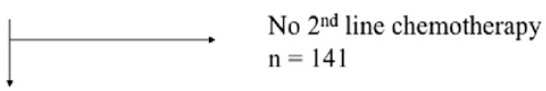

$2^{\text {nd }}$ line chemotherapy, $\mathrm{n}=162(39.9 \%)$

Number of cycles: $3.5 \pm 1.9$

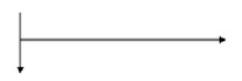

No $3^{\text {rd }}$ line chemotherapy

$3^{\text {rd }}$ line chemotherapy, $\mathrm{n}=56(13.8 \%)$ $\mathrm{n}=106$

Number of cycles: $3.1+/-2$

Fig. 1 Chemotherapy administration

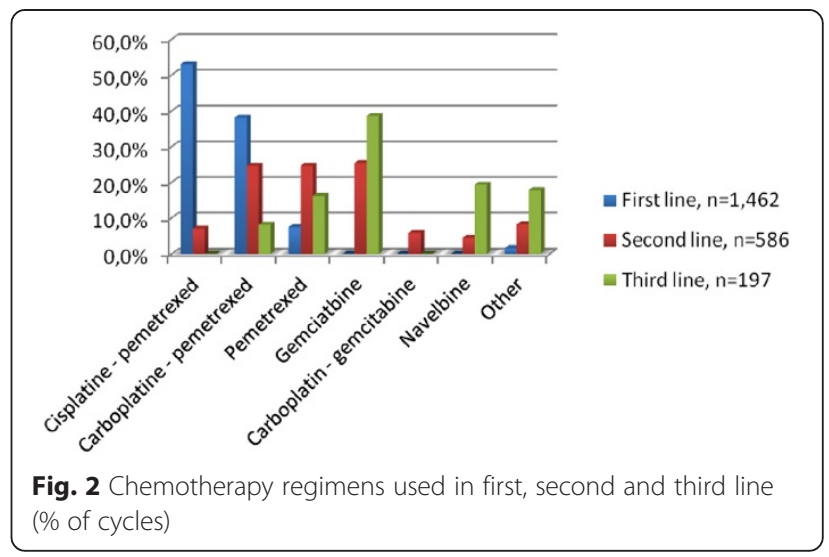

center, age was also younger (60.3 years for men), male predominance was moderate $(55.6 \%)$ and epithelioïd type accounted for only $50 \%$ of the tumors [11]. These findings suggest that the epidemiology of mesothelioma is different in France and Eastern European countries, where tumors are more frequent in women and occur at younger ages, with a different distribution of histological types. Indeed, it is well known that in Turkey, environmental exposure is frequent due to opencast asbestos mines, and genetic predisposition has been shown in some regions [12].

Table 3 Clinical response

\begin{tabular}{ll}
\hline First line chemotherapy $(n=303)$ & \\
Complete response & $9(3.0 \%)$ \\
Partial response & $43(14.2 \%)$ \\
Stable disease & $126(41.6 \%)$ \\
Disease control $(C R+P R+S D)$ & $178(58.8 \%)$ \\
Progression & $99(32.7 \%)$ \\
Non evaluable & $26(8.5 \%)$ \\
Second line chemotherapy $(n=162)$ & \\
Complete response & $1(0.6 \%)$ \\
Partial response & $9(5.4 \%)$ \\
Stable disease & $31(18.6 \%)$ \\
Disease control $(C R+P R+S D)$ & $41(24.6 \%)$ \\
Progression & $78(46.7 \%)$ \\
Non evaluable & $48(28.7 \%)$ \\
Third line chemotherapy $(n=56)$ & \\
Complete response & 0 \\
Partial response & $1(1.8 \%)$ \\
Stable disease & $2(3.6 \%)$ \\
Disease control $(C R+P R+S D)$ & $3(5.4 \%)$ \\
Progression & $27(48.2 \%)$ \\
Non evaluable & $26(46.4 \%)$ \\
\hline
\end{tabular}


The latency in our cohort was 45.7 years, which is consistent with other epidemiological studies $[1,3,4]$. It has been shown that apart from intensity and duration of exposure, the risk of MPM is inversely correlated with the age at first exposure [13]. However, this information has not been recorded in our patients' files.

During the 2003-2007 5-year period, the pathological branch of the PNSM network (a mandatory, national review) analyzed 1348 pleural biopsies, among which $82 \%$ were malignant mesotheliomas [6]. In this large sample of MPM, $80 \%$ were epithelioïd, $6 \%$ were sarcomatoid and $11 \%$ were biphasic. Although our study included only $1 / 10^{\text {th }}$ of the estimated total number of cases of MPM diagnosed in France in the same period, the distribution of histological types is very similar to ours and these data suggest that our cohort is representative of MPM in France.

Main guidelines in the diagnosis and management of MPM are those issued by the European Respiratory Society - European Society of Thoracic Surgeons (ERSESTS) [14] and those issued by the European Society of Medical Oncology (ESMO) [15]. The use of positron emission tomography (PET) scanning is still under debate because MPM tends to only grow locally and metastases occur solely in patients with advanced disease but PET scanning can be used in the diagnostic work-up when

PET-avid sites in the thoracic cavity need to be identified to obtain representative tissue. In this analysis, only $24 \%$ of the patients had a Pet scan as initial procedure; this can be explain by a limited access to this test in France, particularly at the study period. From a diagnostic perspective, thoracoscopy is recommended by ERSESTS for the pathological diagnosis of MPM, using deep and large biopsies while cytology and fine needle biopsies are considered insufficient. The ESMO also states that histology is the gold standard, using pleuroscopy or open pleural biopsy. In our series, almost all atients had a MPM diagnosis based on histology, biopsies being obtained by thoracoscopy and thoracotomy in the majority of cases.

Few options are available for the treatment of MPM and its prognosis remains very poor with a median overall survival below 12 months [16]. Extrapleural pneumonectomy does not offer survival benefits and it is accompanied by high morbidity and mortality [9, 17]. Both ERS-ESTS and ESMO guidelines recommend that extrapleural pleurectomy be performed only in a palliative setting to obtain symptoms control, and that radical surgery be performed only in highly specialized centers, as part of clinical trials, in a multimodal approach. In our series, only $30(7.4 \%)$ patients underwent surgery with curative intent. Of note, the results of the MARS study [9] had not been published at this time.
Prophylactic irradiation of tracks, intending to avoid tumor seeding after chest drain or pleural biopsy, is not recommended due to discrepancies between the few studies and to insufficient data [8-21]. Despite this recommendation, in our study, a large part of patients, $65.5 \%$ received a prophylactic irradiation of tracks.

According to guidelines, when the decision is made to administer chemotherapy, first line treatment should consist of platinum associated with pemetrexed or raltitrexed [14, 22, 23]. This recommendation was followed by the French sites in our study since $91 \%$ of first-line regimens consisted of platinum + pemetrexed.

In the initial study published by Vozelgang et al. in 2003, pemetrexed plus cisplatin was compared to cisplatin alone in chemonaïve patients [22]. The combination with pemetrexed resulted in longer overall survival (12.1 vs 9.3 months, $p=0.02$ ), and increased response rates ( 41.3 vs $16.7 \%, p<0.0001)$. In our cohort, only $17.5 \%$ of patients responded to this first-line chemotherapy, while the median number of cycles [6] was similar. According to the preliminary results of an Italian cohort of patients $(n=322)$ receiving pemetrexed alone (28\%) or associated with cisplatin or carboplatin, the overall response rate was $28.5 \%$ [24]. However, in the phase II study published in 2006 by Ceresoli et al., only $18.6 \%$ of patients treated with pemetrexed + carboplatin $(19 / 102)$ had an objective response, including 2 CR and $17 \mathrm{PR}$, while $65.7 \%$ achieved disease control, which is more consistent with our findings [25]. However, the response rate observed in our retrospective cohort seems low and has to be considered with caution. Indeed, in our study, there was no centralized review of the response to treatment and the follow-up of the patients was not standardized.

Drugs to be used in second line are not well-defined: guidelines suggest, with low levels of evidence, re challenge with the initial combination in case of response, or vinorelbine, or inclusion in clinical trials $[14,15]$. In our series, the response rate was very low in the second-line setting (6\%) and only $24.6 \%$ of patients had disease control. This result rate is consistent with that observed in a US study (2\%) that retrospectively reviewed the outcome of gemcitabine and/or vinorelbine chemotherapy in pemetrexed pretreated patients [26]. However, in this series of 60 patients, $46 \%$ had stable disease, which is much higher than in ours. In another trial, vinorelbine single agent administered as second or further line chemotherapy in pemetrexed pretreated patients yielded a $15.2 \%$ response rate and $33.9 \%$ stable disease [27]. In a Japanese study, gemcitabine + vinorelbine administered as second line or beyond to pemetrexed pretreated patients resulted in $18 \%$ response rate and $82 \%$ disease control [28]. Retreatment with pemetrexed (alone or in combination, second or further line) appears a valuable 
option with a $19 \%$ response rate and $48 \%$ disease control rate in an Italian study [29]. Response to rechallenge appears to be correlated with response to first line pemetrexed-based chemotherapy.

Due to the methodology of our study, several data are missing because they are not systematically reported in medical records in routine practice. We could not establish survival curves since we did not collect longitudinal data. However, we could show that our patients are representative of the French MPM patients, that recommendations are appropriately followed with regards to both diagnostic procedures and treatment, and that unfortunately, treatment outcomes in daily practice are not as good as those reported in clinical trials. Actually, new treatment options are urgently needed to improve patients' prognosis. Targeted therapies yielded disappointing results up to now [7] and further results are eagerly awaited, such as those of the MAPS study [30]. In the recent ASCO congress, promising results from new and original approaches such as arginine deprivation [31] or vaccines [32] were reported. However, these data must be considered very cautiously, until they are confirmed in further studies.

\section{Conclusion}

We showed in this study that the management of MPM in France is in line with European recommendations. Yet, treatment outcomes remain disappointing, usually lower in routine practice than in clinical trials. New treatment options are urgently needed to improve the prognosis of MPM.

\section{Competing interests}

In the last five years, Christos Chouaid has received honoraria for attending scientific meetings, speaking, organizing research or consulting, from Astra Zeneca, Boehringer Ingelheim, GlaxoSmithKline, Hoffman-la Roche, Sanofi Aventis, Lilly, Novartis and Amgen. The others authors declare no disclosures in relation with the topic to this manuscript.

\section{Authors' contributions}

$\mathrm{CR}, \mathrm{GL}, \mathrm{BI}, \mathrm{CC}$ had full control of the study design, data analysis, interpretation and manuscript preparation. CR,CC and IB conceived and performed the statistical analysis, MJ, MI, MB, FG, DA participated in the design, $B H, L R, L J, L H$, OG coordinate the study, BS, VA, IB helped to draft the manuscript. All authors read and approved the final manuscript.

\section{Acknowledgments}

This trial was an academic trial conducted by Groupe Français de Pneumo Cancerologie (GFPC). This study received public funding and an unrestricted grant from Lilly France.

\section{Prior presentation}

This study was presented at the WLCC meeting in Sydney 2013

\section{Author details}

${ }^{1}$ Service de Pneumologie, CH Argenteuil, Argenteuil, France. ${ }^{2}$ Service d'oncologie thoracique, APHM, Marseille, Services de Pneumologie, Marseille, France. ${ }^{3} \mathrm{CHU}$ Toulouse, Toulouse, France. ${ }^{4}$ Service de pneumologie, $\mathrm{CHI}$ Créteil, 40 avenue de verdun, 94010 Créteil, France. ${ }^{5} \mathrm{CHU}$ Lyon, Lyon, France. ${ }^{6} \mathrm{CHU}$ Brest, Brest, France. ${ }^{7} \mathrm{CH}$ Cergy Pontoise, Cergy Pontoise, France. ${ }^{8} \mathrm{CH}$ d'Orléans, Orléans, France. ${ }^{9} \mathrm{HI}$ A Toulon, Toulon, France. ${ }^{10} \mathrm{CH}$ Lorient, Lorient,
France. ${ }^{11} \mathrm{CH}$ Aix en Provence, Aix en Provence, France. ${ }^{12} \mathrm{CHU}$ Rennes, Rennes, France. ${ }^{13} \mathrm{CH}$ Longjumeau, Longjumeau, France. ${ }^{14} \mathrm{CHU}$ Rouen, Rouen, France. ${ }^{15} \mathrm{CHU}$ Limoges, Limoges, France. ${ }^{16} \mathrm{IGR}$, Villejuif, France.

Received: 25 January 2015 Accepted: 30 October 2015

Published online: 06 November 2015

\section{References}

1. Reid A, de Klerk NH, Magnani C, Ferrante D, Berry G, Musk AW, et al. Mesothelioma risk after 40 years since first exposure to asbestos: a pooled analysis. Thorax. 2014;69:843-50.

2. Ceresoli GL, Gridelli C, Santoro A. Multidisciplinary treatment of malignant pleural mesothelioma. Oncologist. 2007;12:850-63.

3. Hodgson JT, McElvenny DM, Darnton AJ, Price MJ, Peto J. The expected burden of mesothelioma mortality in Great Britain from 2002 to 2050. Br J Cancer. 2005;92:587-93.

4. Robinson BM. Malignant pleural mesothelioma: an epidemiological perspective. Ann Cardiothorac Surg. 2012;1:491-6.

5. Campbell K, Brosseau S, Reviron-Rabec L, Bergot E, Lechapt E, Levallet G, et al. Malignant pleural mesothelioma: 2013 state of the art. Bull Cancer. 2013;100:1283-93.

6. Galateau-Salle F, Gilg Soit Ilg A, Le Stang N, Brochard P, Pairon JC, et al. The French mesothelioma network from 1998 to 2013. Ann Pathol. 2014;34:51-63.

7. Nowak AK. Chemotherapy for malignant pleural mesothelioma: a review of current management and a look to the future. Ann Cardiothorac Surg. 2012;1:508-15.

8. Van Schil PE, Baas P, Gaafar R, Maat AP, Van de Pol M, Hassan B, et al. Trimodality therapy for malignant pleural mesothelioma: results from an EORTC phase II multicentre trial.

Eur Respir J. 2010;36:1362-9.

9. Treasure T, Lang-Lazdunski L, Waller D, Bliss JM, Tan C, Entwisle J, et al. Extra-pleural pneumonectomy versus no extra-pleural pneumonectomy for patients with malignant pleural mesothelioma: clinical outcomes of the Mesothelioma and Radical Surgery (MARS) randomised feasibility study. Lancet Oncol. 2011;12:763-72.

10. Berk S, Dogan OT, Kilickap S, Epozturk K, Akkurt I, Seyfikli Z. Clinical characteristics, treatment and survival outcomes in malignant mesothelioma: eighteen years' experience in Turkey. Asian Pac J Cancer Prev. 2012;13:5735-9.

11. Sezer A, Sumbul AT, Abali H, Mertsoylu H, Ozyilkan O. Malignant pleural mesothelioma: a single-center experience in Turkey. Med Sci Monit. 2014;20:825-32.

12. Ray M, Kindler HL. Malignant pleural mesothelioma: an update on biomarkers and treatment. Chest. 2009;136:888-96.

13. Lacourt A, Leffondre K, Gramond C, Ducamp S, Rolland P, Gilg A, et al. Temporal patterns of occupational asbestos exposure and risk of pleural mesothelioma. Eur Respir J. 2012;39:1304-12.

14. Scherpereel A, Astoul P, Baas P, Berghmans T, Clayson H, de Vuyst P, et al. Guidelines of the European Respiratory Society and the European Society of Thoracic Surgeons for the management of malignant pleural mesothelioma. Eur Respir J. 2010:35:479-95.

15. Baas P, Fennell D, Kerr KM, Van Schil PE, Haas RL, Peters S, et al. Malignant pleural mesothelioma: ESMO Clinical Practice Guidelines for diagnosis, treatment and follow-up. Ann Oncol. 2015;00:1-9. doi:10.1093/annonc/mdv199.

16. Porpodis K, Zarogoulidis P, Boutsikou E, Papaioannou A, Machairiotis N, Tsakiridis K, et al. Malignant pleural mesothelioma: current and future perspectives. J Thorac Dis. 2013;5:S397-406.

17. Burt BM, Cameron RB, Mollberg NM, Kosinski AS, Schipper PH, Shrager JB, et al. Malignant pleural mesothelioma and the Society of Thoracic Surgeons Database: an analysis of surgical morbidity and mortality. J Thorac Cardiovasc Surg. 2014;148:30-5

18. Boutin C, Rey F, Viallat JR. Prevention of malignant seeding after invasive diagnostic procedures in patients with pleural mesothelioma. A randomized trial of local radiotherapy. Chest. 1995;108:754-8.

19. O'Rourke N, Garcia JC, Paul J, Lawless C, McMenemin R, Hill J. A randomised controlled trial of intervention site radiotherapy in malignant pleural mesothelioma. Radiother Oncol. 2007;84:18-22.

20. Chapman E, Berenstein EG, Dieguez M, Ortiz Z. Radiotherapy for malignant pleural mesothelioma. Coch Database Sysc Rev. 2006;CD003880. 
21. Société de Pneumologie de Langue Française. Recommandations de la Société de Pneumologie de Langue Française sur le mésothéliome pleural. Rev Mal Respir. 2006;23:11S7.

22. Vogelzang NJ, Rusthoven JJ, Symanowski J, Denham C, Kaukel E, Ruffie P, et al. Phase III study of pemetrexed in combination with cisplatin versus cisplatin alone in patients with malignant pleural mesothelioma. J Clin Oncol. 2003;21:2636-44.

23. van Meerbeeck JP, Gaafar R, Manegold C, an Klaveren RJ, Van Marck EA, Vincent $\mathrm{M}$, et al. Randomized phase III study of cisplatin with or without raltitrexed in patients with malignant pleural mesothelioma: an intergroup study of the European Organisation for Research and Treatment of Cancer Lung Cancer Group and the National Cancer Institute of Canada. J Clin Oncol. 2005;23:6881-9.

24. Marangolo M, Vertogen B. Pemetrexed and malignant pleural mesothelioma. Ann Oncol. 2006;17:v103-5.

25. Ceresoli GL, Zucali PA, Favaretto AG, Grossi F, Bidoli P, Del Conte G, et al. Phase II study of pemetrexed plus carboplatin in malignant pleural mesothelioma. J Clin Oncol. 2006;24:1443-8.

26. Zauderer MG, Kass SL, Woo K, Sima CS, Ginsberg MS, Krug LM. Vinorelbine and gemcitabine as second- or third-line therapy for malignant pleural mesothelioma. Lung Cancer. 2014;84:271-4.

27. Zucali PA, Perrino M, Lorenzi E, et al. Vinorelbine in pemetrexed-pretreated patients with malignant pleural mesothelioma. Lung Cancer. 2014;84:265-70.

28. Toyokawa G, Takenoyama M, Hirai F, Toyozawa R, Inamasu E, Kojo M, et al. Gemcitabine and vinorelbine as second-line or beyond treatment in patients with malignant pleural mesothelioma pretreated with platinum plus pemetrexed chemotherapy. Int J Clin Oncol. 2013. [Epub ahead of print].

29. Ceresoli GL, Zucali PA, De Vincenzo F, Colombo P, Simonelli M, Lorenzi E, et al. Retreatment with pemetrexed-based chemotherapy in patients with malignant pleural mesothelioma. Lung Cancer. 2011;72:73-7.

30. Zalcman G, Mazieres J, Margery J, et al. Bevacizumab $15 \mathrm{mg} / \mathrm{kg}$ plus cisplatinpemetrexed (CP) triplet versus CP doublet in Malignant Pleural Mesothelioma (MPM): Results of the IFCT-GFPC-0701 MAPS randomized phase 3 trial. ASCO meeting Abstract. J Clin Oncol 2015;33 (suppl; abstr 7500).

31. Szlosarek PW, Nolan JP, Gilligan L, Luong P, Phillips MM, Baccarini M, et al. Randomized trial of arginine deprivation with pegylated arginine deiminase in patients with malignant pleural mesothelioma. J Clin Oncol. 2014;32:A7507.

32. Hassan RA, Kindler EW, Antonia HL, Kondo E, Kawamoto H, Hassan W, et al. Antimesothelin vaccine CRS-207 plus chemotherapy as front-line treatment for malignant pleural mesothelioma (MPM). J Clin Oncol. 2014;32:A7532.

\section{Submit your next manuscript to BioMed Central and take full advantage of:}

- Convenient online submission

- Thorough peer review

- No space constraints or color figure charges

- Immediate publication on acceptance

- Inclusion in PubMed, CAS, Scopus and Google Scholar

- Research which is freely available for redistribution

Submit your manuscript at www.biomedcentral.com/submit 